\title{
THE ROLE OF FLUORIDE ON ERUPTION OF MANDIBULAR MOLAR OF ALBINO RATS
}

Omowumi M. Femi-Akinlosotu1 BDS, PhD; Olakayode O. Ogundoyin1,2 fWACS; Morenike A. Akintola1 BDS, MSc.

1Department of Anatomy, College of Medicine, University of Ibadan. Ibadan. Nigeria. 2Department of Surgery, College of Medicine, University of Ibadan. Ibadan. Nigeria.

Correspondence to Omowumi M. Femi-Akinlosotu. Department of Anatomy, College of Medicine, University of Ibadan. Ibadan. Nigeria. Email: omowumiakinlosotu@gmail.com. Phone: +234-703116-3053

\begin{abstract}
Eruption of the tooth is a complex and highly regulated process which can be influenced by genetic, environmental and systemic factors. Fluoride is found naturally in water as well as in foods and dental products. The first mandibular molar is the first molar to erupt and it is essential for mastication of food. We studied the effect of fluoride on the eruption of the first mandibular molar in albino rats.

Fluoride at different concentrations was added to the water of pregnant albino rats while sterile water without fluoride was given to the control pregnant dams. The pregnant dams were allowed to deliver, and the heads of their pups carefully decapitated, and mandibles dissected out on days 10,12, 15 and 18 for assessment of eruption pattern of the first molar while also measuring the mandibular length and breadth. The mandibles were then processed for hematoxylin and eosin staining. On gross examination, some of the teeth developed intraosseously while others were located mucosally, preocclusally or occlusally. There was significant reduction in both the birth weight and mandibular length as the fluoride concentration increased compared to the control but a significant increment in the mandibular breadth between the experimental groups in comparison with the control group on day 15 ( $p$ value <0.05). These findings suggest that high concentrations of fluoride could delay mandibular molars' eruption and also cause low birth weight.
\end{abstract}

Key Words: fluoride, mandibular molar, tooth eruption

\section{INTRODUCTION}

Tooth eruption is a complex process that involves the movement of the tooth from its site of development in alveolar bone to the occlusal plane in the oral cavity. This process can however be influenced by a number of general factors like genetic, environmental and systemic factors. The growth becomes delayed when it deviates significantly from its normal set time of eruption (Almonaitiene et al., 2010). Fluoride is one of the most toxic substances present in the earth's crust, more toxic than lead and only marginally less so than arsenic and mercury with documented adverse effects on bones, teeth, stomach, liver, kidneys and thyroid gland (Gibson, 1998). Naturally occurring fluoride in water, can cause many problems at high levels and is more toxic when added to water supplies in the form of fluorosilicic acid, a waste product of the phosphate fertilizer industry that is part of a pollution concentrate that is heavily contaminated with toxins and heavy metals, such as arsenic, lead, cadmium (all carcinogens) and radioactive materials (Stockton, 2004). Fluoride exposed to the developing tooth increases the formation of morphologically and chemically unstable crystals resulting in reduced degradation of mature tooth tissue (Robinson et. al., 2004). Moreover, fluoride can be mitogenic at low doses as well as toxic at high doses (Everett, 2011).

Fluoride-containing products such as toothpastes, gels, mouth rinses and varnishes are getting more popularity worldwide (Tao et al., 2018). Fluoride ingestion interferes with many basic vital functions in the body by inhibiting enzyme activity, interfering with the use of oxygen by cells and accelerating the 
breakdown of collagen (the body's major structural protein). Fluoride has a very strong affinity for hydrogen which is the major molecule which links DNA together (Yiamouyiannis, 1983). Fluoride in water at 1 $\mathrm{mg} / \mathrm{L}$ causes dental fluorosis, the first visible sign of fluoride toxicity. It has an inhibitory effect on the functional abilities of white blood cells, an integral part of the immune system, thus predisposing sensitive individuals to cancer, since one of the functions of the immune system is to find and destroy developing cancer cells. Dental fluorosis has been documented to result from drinking high fluoridated water which could also be risky to the developing skeletal system (Kierdorf et. al., 2016). Fluoride may also interact with mineralized tissues and when present in excess disturbs dental enamel development (MartinezMier et. al., 2016). Tooth eruption may be delayed significantly if fluoridation is carried out as observed in comparison between fluoridated areas and un-fluoridated areas (Yiamouyiannis, 1990). Apart from its dental implications in high doses, fluoride ions can also be emitted from atmospheric volcanic emissions and volcanic aquifers. In fact, certain geographic regions are exposed to fluoride from volcanic activity and groundwater. This can be significant and may result in chronic fluoride intoxication (Waugh et al., 2016). Kierdorf and Colleagues noticed developmental and post-eruptive defects in the molar enamel of free ranging Kangaroos (Macropus giganteus) exposed to high environmental levels of fluoride and concluded that the observed defects denote a fluoride-induced disturbance of tooth development and maturation (Kierdorf et. al., 2016).

In this study we seek to verify if fluoride ingested with water is detrimental rather than beneficial in causing delay in tooth eruption by experimenting with albino rat molar teeth. Therefore, we intend to find out if all fluoridated pregnant rats produced litters with delayed tooth eruption using macroscopic and histological evaluation.

\section{MATERIALS AND METHODS}

Forty-five female and ten male albino adult rats weighing $120-200 \mathrm{~g}$, were obtained from College of Medicine Animal House, University of Ibadan. A male rat is kept with three females for the purpose of mating and the presence of vagina plug on examination of their vagina indicates successful mating and conception. The day the vagina plug is found is recorded as day 0 . The control group were given water without fluoride inclusion in their drinking water while the experimental groups were given fluoridated water and were grouped according to the fluoride contents of their water. The rats were grouped as follows:

GROUP
I
II
III
IV
V

Control without fluoridated drinking water
$10 \mathrm{mg} / \mathrm{L}$ of fluoride in drinking water
$20 \mathrm{mg} / \mathrm{L}$ of fluoride in drinking water
$80 \mathrm{mg} / \mathrm{L}$ of fluoride in drinking water
$100 \mathrm{mg} / \mathrm{L}$ of fluoride in drinking water

The pups were further subdivided into control (those that sucked breast milk only) and the rest were classified as experimental (those that were further given fluoridated water as well as their mothers). The fluoridated groups (pups) were given three drops of fluoridated water through pasture plastic pipette.

\begin{tabular}{cl} 
GROUP & \multicolumn{1}{c}{ DESCRIPTION } \\
I & $\begin{array}{l}\text { pups of control group not given fluoride } \\
\text { IIa }\end{array}$ \\
pups in group II were on breast milk and \\
daily administration of $10 \mathrm{mg} / \mathrm{L}$ \\
IIIa & $\begin{array}{l}\text { pups in group III were on breast milk and } \\
\text { daily administration of } 20 \mathrm{mg} / \mathrm{L}\end{array}$ \\
IVa & $\begin{array}{l}\text { pups in group V were on breast milk and } \\
\text { daily administration of } 80 \mathrm{mg} / \mathrm{L}\end{array}$ \\
Vaps in group VI were on breast milk and \\
daily administration of $100 \mathrm{mg} / \mathrm{L}$
\end{tabular}

Sodium fluoride salt (Guangdong Guanghua Chemical Factory Co. Ltd., Shantou Guangdong, China) was measured with digital weighing scale (My Weigh i201 with capacity $200 \mathrm{~g}, \mathrm{~d}=0.01$ ) and then mixed with a litre of distilled water to obtain the different concentration. The solution was given to each group before and during pregnancy till birth and then till the 18th post-natal day. The animals were weighed, and the gross assessment of their mandibular jaw was done using stereomicroscope (Optika Microscopes, 
ST-40-2L, Via Rigia 32 24010, Ponteranica BG, Italy). The length and breadth of the mandible were measured with electronic digital calliper (Titan 23175).

The animals were sacrificed on days $10,12,15,18$ and their heads decapitated after anaesthetizing with cotton wool soaked in chloroform (all procedures of sacrifice avoided animal suffering at each stage of the experiment as much as possible). Their jaws were carefully dissected out and stored in $10 \%$ formalin solution.

\section{Gross evaluation of eruption}

\section{RESULTS}

Rats given fluoridated water were noticed to have delayed reproductive ability especially those on lower doses $(10 \mathrm{mg} / \mathrm{L}$ and $20 \mathrm{mg} / \mathrm{L})$. Eruption of the first molar was checked on days $10,12,15$ and 18. Criteria for classification were: 1- no evidence of tooth eruption (no eruption); 2 - appearance of cuspal edges (erupting); 3- tooth showing (erupted). It was observed that there was $100 \%$ no eruption on day 10 of control and experimental groups.

On day 12 , there was no eruption in the control group; group II had $16.7 \%$ erupting, $83.3 \%$ no eruption; group III had $9.09 \%$ erupting, $90.91 \%$ no eruption; group IV had $100 \%$ no eruption, group $\mathrm{V}$ had $25 \%$ erupting, $75 \%$ no eruption (Figure 1A). On day 15 (Figure 1B), group I had $75 \%$ erupting, $25 \%$ no eruption; group II had $25 \%$ erupting $75 \%$ no eruption; groups III and IV had $100 \%$ erupting whereas group $V$ had $68.75 \%$ erupted and $31.25 \%$ erupting. On day 18 (Figure $1 \mathrm{C}$ ), the $20 \mathrm{~g} / \mathrm{L}$ and $80 \mathrm{mg} / \mathrm{L}$ groups had $100 \%$ erupted whereas the $100 \mathrm{mg} / \mathrm{L}$ group had $66.7 \%$ erupted and $33.3 \%$ erupting. Figure 2 revealed the different eruption pattern of the molars at different concentration of fluoride intake. The cusps of

\section{Histology}

Paraffin embedded tissues sections $(5 \mu)$ were cut and stained with hematoxylin and eosin and then covered with DPX mountant. Photomicrographs of the sections were taken with a Sony digital camera (M340) mounted on an Olympus microscope $(\mathrm{CH} 2 \mathrm{Oi}$; Binocular version) at $\times 40$ magnification.

Data were analyzed using GraphPad Prism Software Version 6.0. All data were expressed as mean \pm standard deviation using ANOVA and Student's t-test and the confidence interval was calculated at $95 \%$ level. the molars were visible as the teeth formed an eruption pathway through the jaw bones.

\section{Weight at birth}

Weight of the pups of the experimental groups when compared with the control group had significant difference $(p=0.0001)$ (Table 1$)$. The mean weight of the pups at birth in the experimental groups II, III, IV and V were 6.98 $\pm 0.49 \mathrm{~g}, 6.96 \pm 0.48 \mathrm{~g}, 6.17 \pm 1.57 \mathrm{~g}$ and 6.09 $\pm 0.93 \mathrm{~g}$ respectively. These were all decreased when compared to the control group $(12.76 \pm 2.51 g)(p<0.0001)$.

\section{Mandibular length}

The lengths of the mandibles $(\mathrm{mm})$ were measured from the occlusal ridge to the base of the mandible (Supplementary 1-4). There were no significant differences in the lengths of the mandibles between the control groups and the experimental groups on days 12 and 15 ( $p=0.1576,0.1927)$. However, there were significant differences in the lengths of the mandibles on days 10 and 18 ( $p=0.045$ and 0.0173 ). The measurements also revealed that there were differences on day 10 as seen in groups III and IV and on day 18 as seen in group IV compared to group I ( $p=0.019$, $0.003,0.032$ respectively). 

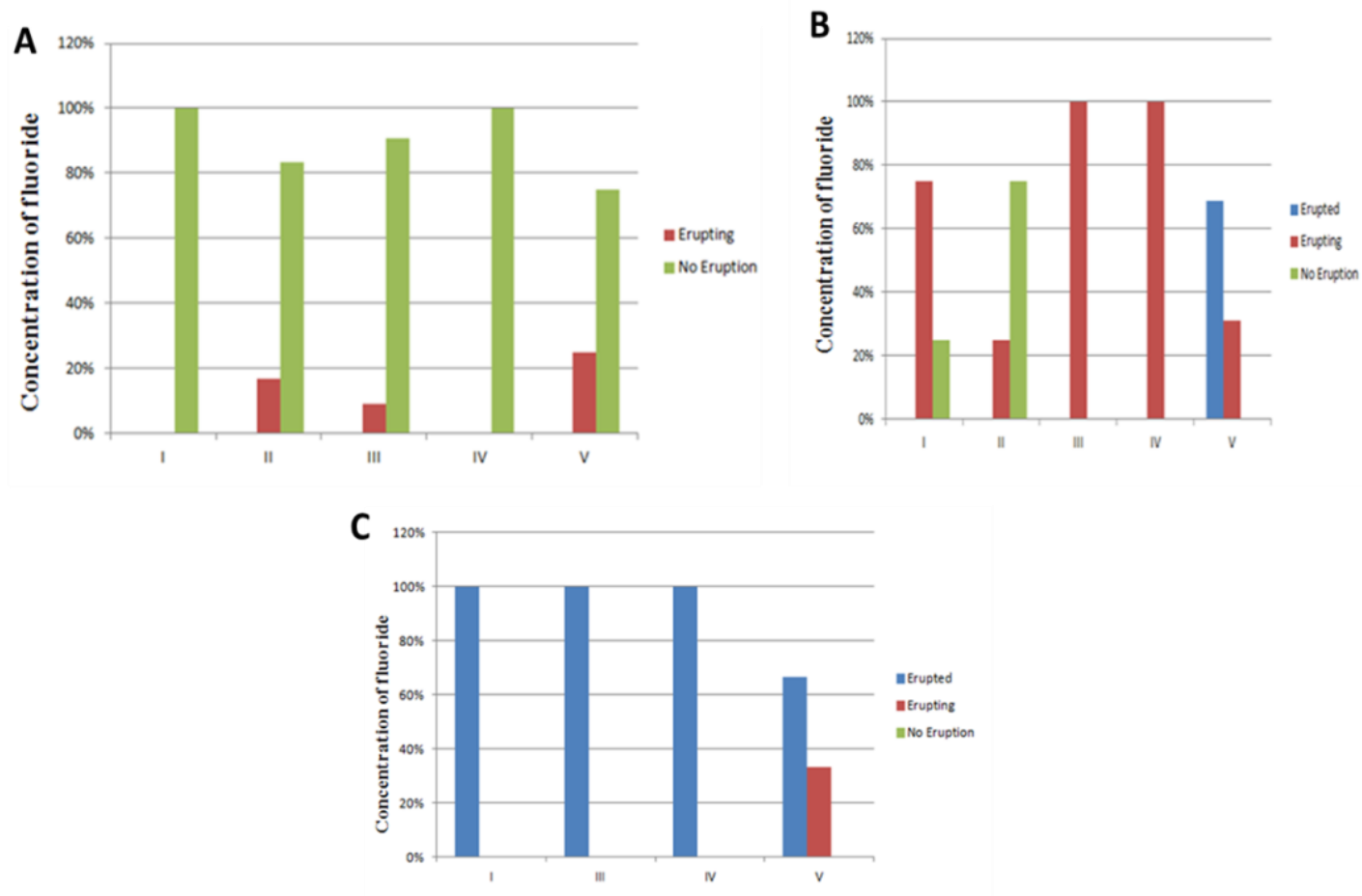

Figure 1: Histograms showing proportion of eruption on day (A)12; (B)15; (C)18

\section{Mandibular breadth}

The mandibular breadths $(\mathrm{mm})$ were measured on the occlusal ridge anteroposteriorly (Supplementary 5-8). There was no significant difference in the breadths of the mandibles between the control group and the experimental group on day $10(p=0.301)$, however, there were significant differences on days 12,15 , and 18 ( $p=0.026,0.011$ and 0.001 respectively). When the control group was compared with the experimental groups on these days, there were significant differences with group IV on day 12 , group $\mathrm{V}$ on day 15 and groups IIII and IV on day 18 $(p<0.05)$.

\section{Cuspal length}

The lengths of the mandibular molar cusps were measured $(\mathrm{mm})$ from the mandibular ridge to the tip of the cusp. These were compared between the control group and the experimental group on day 18 (Table 2). There was significant difference between the cuspal length of group I and groups III, IV and V ( $p<$ 0.05).

\section{Microscopy}

Following histological preparations with hematoxylin and eosin staining methods, microscopic observations of the developing and erupting teeth revealed that most of the teeth at days 10 and 12 were still intraosseous (not erupting) whereas those on day 15 had their cusps near the alveolar junction (mucosal stage of eruption) and day 18 revealed that the cusps were out of the alveolar junction making the teeth to be in either pre-occlussal or occlusal stage depending on the extent of eruption (Figure 3 ). 
Anatomy Journal of Africa. 2020. Vol 9 (1): 1752 - 1761.
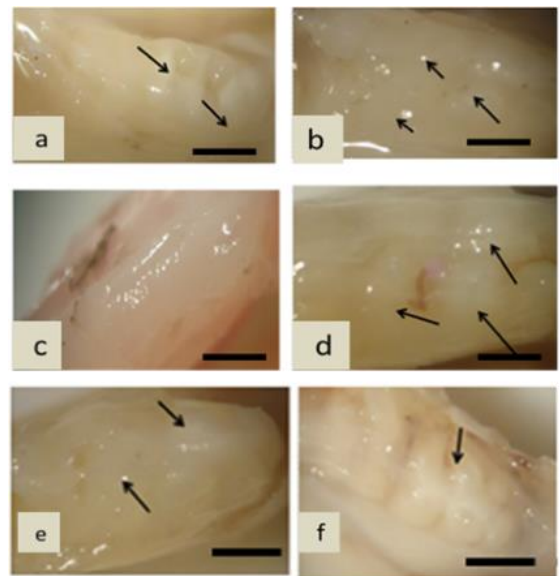

Figure 2: Erupting cusps of molars (arrows) on day $12,15,18$ (a) $10 \mathrm{mg} / \mathrm{L}$ (b) $20 \mathrm{mg} / \mathrm{L}$ (c) $80 \mathrm{mg} / \mathrm{L}$ (d) $100 \mathrm{mg} / \mathrm{L}$ (e) control (f) $10 \mathrm{mg} / \mathrm{L}(\mathrm{g})$ $20 \mathrm{mg} / \mathrm{L}$ (h) $80 \mathrm{mg} / \mathrm{L}$ (j) control (k) $20 \mathrm{mg} / \mathrm{L}(\mathrm{l})$ $80 \mathrm{mg} / \mathrm{L}(\mathrm{m}) 100 \mathrm{mg} / \mathrm{L}$; (j: occlusal; k,l,m: preocclusal; arrows on erupting 1st molar). Scale bar - $20 \mu \mathrm{m}$
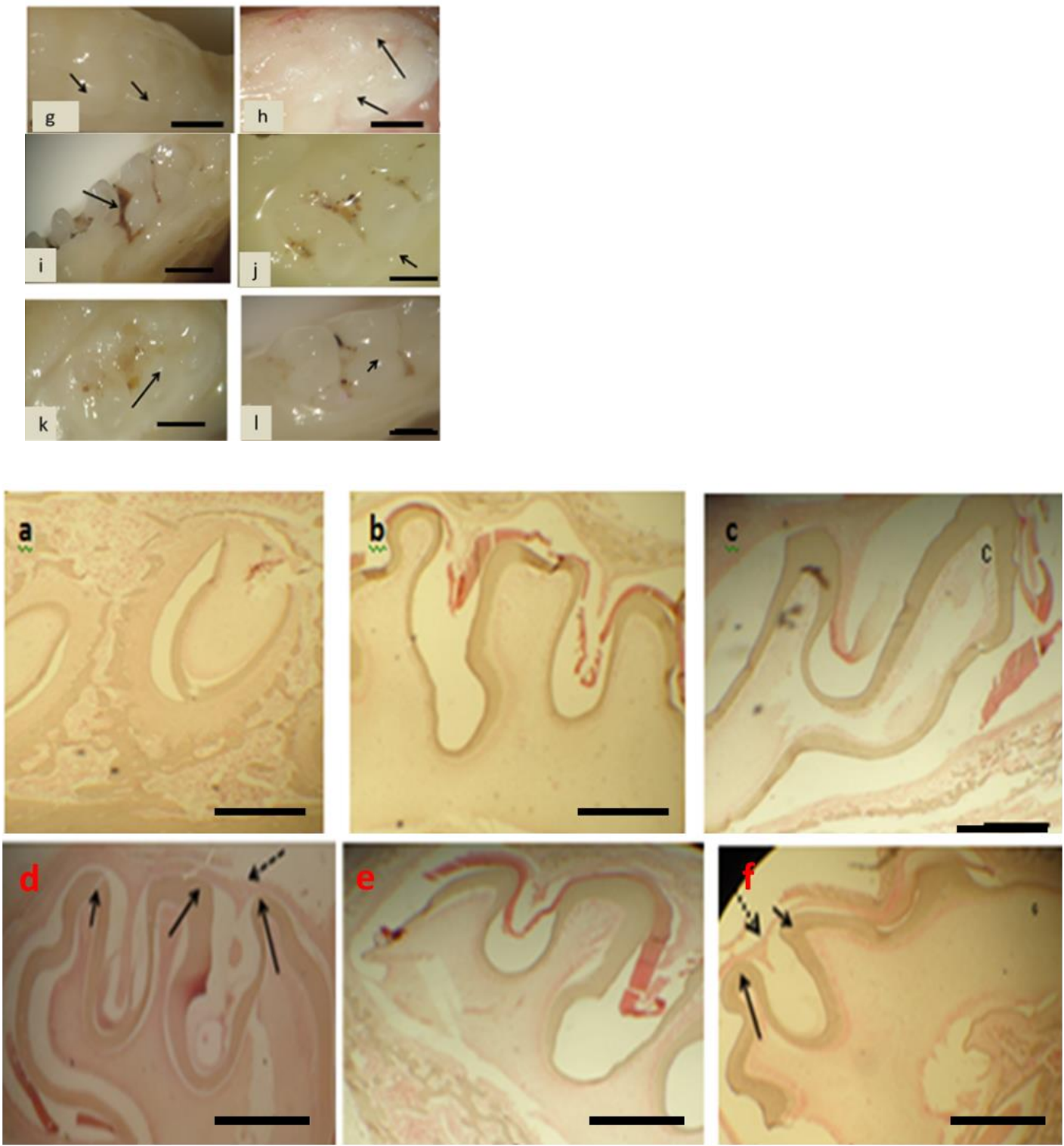

Figure 3: Hematoxylin and eosin stained photomicrograph of intraosseous development on day 10 and 15 (a) control (b) $10 \mathrm{mg} / \mathrm{L}$ (c) $100 \mathrm{mg} / \mathrm{L}$ (d) control (e) $10 \mathrm{mg} / \mathrm{L}$; (f) $100 \mathrm{mg} / \mathrm{L}$ of fluoride. Bold arrows on erupting cusps; dashed arrows on alveolar junction with mucosa. Scale bar $-20 \mu \mathrm{m}$ 
Table 1: Weight (g) at birth at different concentrations of fluoride

\begin{tabular}{|c|c|c|c|c|c|c|c|c|}
\hline Group & \multicolumn{2}{|c|}{$\begin{array}{c}\mathrm{I} \\
\text { (control) }\end{array}$} & \multicolumn{2}{|c|}{$\begin{array}{c}\mathrm{I} \\
\text { (control) }\end{array}$} & \multicolumn{2}{|c|}{$\begin{array}{c}\mathrm{I} \\
\text { (control) }\end{array}$} & \multicolumn{2}{|c|}{$\begin{array}{c}\mathrm{I} \\
\text { (control) }\end{array}$} \\
\hline & 12.05 & 7.07 & 12.05 & 7.21 & 12.05 & 4.00 & 12.05 & 5.55 \\
\hline & 11.71 & 7.02 & 11.71 & 6.29 & 11.71 & 4.72 & 11.71 & 5.29 \\
\hline & 13.25 & 7.00 & 13.25 & 6.51 & 13.25 & 5.46 & 13.25 & 6.31 \\
\hline & 11.22 & 5.60 & 11.22 & 7.22 & 11.22 & 5.82 & 11.22 & 5.36 \\
\hline & 19.92 & 7.10 & 19.92 & 7.00 & 19.92 & 4.18 & 19.92 & 5.57 \\
\hline & 12.11 & 7.25 & 12.11 & 6.59 & 12.11 & 4.40 & 12.11 & 5.53 \\
\hline & 10.21 & 7.26 & 10.21 & 6.45 & 10.21 & 7.70 & 10.21 & 4.48 \\
\hline & 11.02 & 6.50 & 11.02 & 7.00 & 11.02 & 7.81 & 11.02 & 6.33 \\
\hline & 11.76 & 7.05 & 11.76 & 7.24 & 11.76 & 7.67 & 11.76 & 6.85 \\
\hline & 14.07 & 7.20 & 14.07 & 7.30 & 14.07 & 7.60 & 14.07 & 7.44 \\
\hline & 13.61 & 7.55 & 13.61 & 8.03 & 13.61 & 6.90 & 13.61 & 7.15 \\
\hline & 12.19 & 7.15 & 12.19 & 6.72 & 12.19 & 7.80 & 12.19 & 7.22 \\
\hline Mean & 12.76 & 6.98 & 12.76 & 6.96 & 12.76 & 6.17 & 12.76 & 6.09 \\
\hline SD & 2.51 & 0.49 & 2.51 & 0.48 & 2.51 & 1.57 & 2.51 & 0.93 \\
\hline $\mathrm{p}$-value & \multicolumn{2}{|c|}{$0.0001 * * *$} & \multicolumn{2}{|c|}{$0.0001^{* * *}$} & \multicolumn{2}{|c|}{$0.0001 * * *$} & \multicolumn{2}{|c|}{$0.0001^{* * *}$} \\
\hline
\end{tabular}

(***statistically significant)

Table 2: Cuspal length at different concentrations of fluoride ( $\mathrm{mm})$ - Day 18

\begin{tabular}{|c|c|c|c|c|c|c|c|c|c|}
\hline Group & & & & & & & Mean & SD & $p$-value \\
\hline I (control) & 1.50 & 1.38 & 1.34 & 1.30 & 1.32 & 1.28 & 1.35 & 0.08 & \multirow[b]{2}{*}{0.034} \\
\hline III & 1.00 & 1.12 & 1.20 & 0.90 & 1.28 & 1.14 & 1.11 & 0.14 & \\
\hline I (control) & 1.50 & 1.38 & 1.34 & 1.30 & 1.32 & 1.28 & 1.35 & 0.08 & \multirow[b]{2}{*}{$0.0001^{* * *}$} \\
\hline IV & 0.80 & 0.73 & 0.92 & 0.87 & 0.82 & 0.95 & 0.85 & 0.08 & \\
\hline I (control) & 1.50 & 1.38 & 1.34 & 1.30 & 1.32 & 1.28 & 1.35 & 0.08 & \multirow[b]{2}{*}{$0.0001^{* * *}$} \\
\hline $\mathrm{V}$ & 1.06 & 0.87 & 0.89 & 0.98 & 0.83 & 0.93 & 0.93 & 0.08 & \\
\hline
\end{tabular}

(***statistically significant)

\section{DISCUSSION}

Tooth eruption is the movement of the tooth from its site of development in alveolar bone to the occlusal plane in the oral cavity (Almonaitiene et. al., 2010). The eruption pattern of the tooth becomes delayed when it deviates significantly from its normal set time of erupting. The eruption process is complex, tightly regulated and divided into five stages: pre-eruptive movement, intraosseous, mucosal penetration, pre-occlusal and post-occlusal stages. Pre-eruptive movements occur during crown formation while the intraosseous stage is the coordinated translocation of the tooth into a resorbed space. Mucosal penetration involves the outer enamel epithelium of the tooth bud proliferating and fusing with the oral epithelium creating the junctional epithelium on the tooth surface, the pre-occlusal eruption stage begins when erupting tooth penetrates the mucosa and the post-occlusal stage starts when the tooth reaches its functional occlusion plane (Proffit and Fields, 2000; Almonaitiene et. al., 2010). Formation of the eruption pathway is completed soon after the cusps reach the alveolar crest and the rate of eruption accelerates (Andreasen et. al., 1997). The tooth eruption process can be influenced by a number of general factors such as genetics, environmental and systemic factors (Almonaitiene et. al., 2010). This study evaluated fluoride as an environmental factor and studies have shown that there is delay in tooth eruption in fluoridated water areas when 
compared to un-fluoridated areas (Hodges et. al., 1941; Yiamouyiannis, 1990; Sutton, 1996). The birth weight of the pups decreased as the concentration of fluoride increased, this is in line with studies done by Susheela and colleagues (Susheela et. al., 2010) as well as Wang and co-researchers (Wang et. al., 2007). The delay in reproductive activities observed in the low fluoride group was contrary to what was observed by Freni (1994) where there was a delay in reproduction with high concentration of fluoride, stating that fluoride inhibits the adenylyl cyclase system in the spermatozoa, ultimately reducing its penetrating competence. Narayana and Chinoy (1994) found that fluoride interferes with androgenesis by altering the concentration and/or configuration of the receptors necessary for this process, thereby inhibiting the action of testosterone. Apart from the aforementioned, the measurement of weight is germane in biological researches because it is the first indication of a developmental anomaly.

The mandibular (largest and hardest facial bone) forms an important source of information in sexual dimorphism (Vinay et. al., 2013) and molar growth and development. Tooth development is influenced by a variety of both genetic and environmental factors one of which is the increase in growth of the mandible. It is believed that the eruption pattern of the posterior teeth can be altered by the decrease in the length and breadth of the mandible. The erupting molars occupy the available spaces on the mandible as they wiggle through the bony crypts, thereby giving rise to a normal alignment or malalignment of the teeth. Even though our study did not find any significant difference in both the mandibular length and breadth of the experimental and control rats, we have been able to generate a data in developmental biology as it relates to eruption pattern of mandibular molars of Albino rats. This may also provide historical information about human food structure, evolution, migration and population relationships (Li Hai Jun et. al., 2012).

Gross observation of the rats' erupting first molar indicates variation in the pattern of eruption with some slight delay in attaining the post-occlusal stage in the experimental groups that were given fluoridated water of different concentrations on different exposure days. On day 10 , there was no eruption of teeth in all the groups as the teeth are still developing within the bone, i.e. intraosseous. On day 12, there was a slight variation in the eruption pattern as few of the mandibles had the 1 st molar in the mucosal stage $(10 \%)$ while the rest were still intraosseous. The variation seen in normal pattern of eruption was seen on day 15 which is similar to what was observed by Almonaitiene and co-authors (Almonaitiene et. al., 2010), regardless of the fluoride concentrations as some of the eruptions were at intraosseous, mucosal and pre-occlusal stages. On day 18 , while the teeth from the control group had reached the post occlusal stage, some of the eruptions from the experimental group were still in mucosal stage especially from the group with high concentrations of fluoride. This occurrence may be due to the effect of the fluoride exposure causing great decrease in the number of osteoclasts which play a major role in the resorption of the alveolar bone necessary for eruption as reported by Krook and Maylin in their experiment where horses' permanent teeth were delayed due to long exposure to high concentrations of fluoride (Krook and Maylin, 1979). Different theories abound in literature on tooth eruption theories. Some of the confirmed theories are root formation, alveolar bone remodelling, periodontal ligament formation, dental follicle (specific cellular changes such as bone forming cells and osteoclastic activities), hormonal influence (pituitary, thyroid), growth factors (epidermal growth factor) and muscular action. The pattern of tooth eruption as well as the sequence of eruption can be affected by the alteration in any of the aforementioned theories. Delay in the eruption of the permanent teeth has also been reported in children in fluoridated communities and the cause of the delay in eruption was because fluoride arrests resorption of deciduous tooth roots and of the supporting bone (Krook and Maylin, 1979). Normally, the resorption of deciduous teeth roots pave way for the erupting permanent teeth through the alveolar bone. There were significant differences in the 
mandibular length on day 10 and 18 . This variation could be due to the accumulation of fluoride in the bone which reduces calcium uptake; thereby influencing growth (San-Xiang et. al., 2007). In the theories of tooth eruption, the growth of the mandible both vertically and horizontally influences the eruption of teeth. As the mandible grow in length in conjunction with the growth and development of the supporting muscles and ligaments, the erupting tooth is facilitated to manoeuvre through the alveolus. These activities can also be summarized into active and passive tooth eruption. The active phase involves the entry of tooth into oral cavity to contact with opposing tooth through the bony crypt. The developing tooth symmetrically increases in size due to forces acting within the tooth follicle. Calcification of the tooth crown provides additional mass against which eruptive forces in the dental follicle can act causing tooth to move occlusally. Bone remodelling trails along the path of erupting tooth, the oral mucosa epithelium becomes continuous with the lining of tooth follicle, reduced enamel epithelium becomes junctional epithelium and there is root-ward migration of gingival tissue and sulcus until the tooth reaches occlusion. However, in the passive phase there is continuous process of adaptation of tooth to changing occlusal relationships after active tooth eruption. Previous studies have also demonstrated multiple effects of exposure to high concentrations of fluoride on growth and development of bones and teeth (Qian et. al., 1989; Xu and Huo, 2000). The significant difference in the mandibular breadth recorded on days 12,15 and 18 could be due to formation of the eruption pathway which is completed soon after the cusps reach the alveolar crest (Andreasen et. al., 1997). Comparison of the cuspal lengths of the experimental groups with the control group suggests that exposure to fluoride causes delay in eruption of the rats' first molars. The crowns of teeth grow in length by the process of ameloblasts (enamel forming cells) differentiation. This process originates at the tip of the cuspal end of the teeth. The rate of differentiation of the enamel forming cells is greater at the cuspal tips than anywhere else on the tooth crown (Dean and Cole, 2013). The importance of the cusps in the life span of the tooth cannot be overemphasized e.g. mastication. Cuspal size and morphology has been implicated as a major factor in tooth patterning in rodents (Cai et. al., 2007). The size of the cusps is determined by both dental mesenchyme and epithelium respectively which co-regulate the morphology of the cusp by the epithelial-mesenchymal interactions. The morphology of the cusp can be mock-up as a reaction diffusion mechanism, in which catalysts and obstacles may determine the teeth patterning. It is however important to study the morphology of the teeth cusps for possible tooth bioengineering.

In conclusion, this study has revealed that there are variations in the eruption pattern of experimental rats' mandibular molars exposed to fluoridated water. However, we support the advocates of fluoride causing delay in the exposure of erupted tooth to cariogenic agents. This research was limited to the use of hematoxylin and eosin staining techniques but special staining techniques as well as immunohistochemistry can be employed to quantify and qualify the process of tooth eruption. Ultrastructural analysis of the affected tissues can also be done using transmission and scanning electron microscopic techniques. We thereby recommend that further research work be carried out with fluoride and its toxic effects on the growth pattern of other intra-oral tissues.

Disclosure Policy: The authors declare that there is no conflict of interests regarding the publication of this paper.

\section{REFERENCES}

1. Almonaitiene R, Balciuniene I, Tutkuviene J. 2010. Factors influencing permanent teeth eruption Part one - general factors. Stomatologija: Baltic Dental and Maxillofacial Journal, 12: $67-72$. 
2. Andreasen JO, Petersen JK, Laskin DM. 1997. Textbook and colour atlas of tooth impactions. St.Louis: Mosby.

3. Cai J, Cho S-W, Kim JY, Lee MJ, Cha YG, Jung HS. 2007. Patterning the size and number of tooth and its cusps. Developmental Biology, vol.304, Issue 2, pg 499-507

4. Dean MC, Cole TJ. 2013. Human Life History Evolution Explains Dissociation between the Timing of Tooth Eruption and Peak Rates of Root Growth. PLoS ONE 8(1): e54534. https://doi.org/10.1371/journal.pone.0054534

5. Everett ET. 2011. Fluoride's Effects on the Formation of Teeth and Bones, and the Influence of Genetics. J. Dent. Res. 90(5): 552-560. doi: 10.1177/0022034510384626

6. Freni SC. 1994. Exposure to high fluoride concentrations in drinking water associated with decreased birth rates. J. Toxicol. Environ. Health 42:109-121

7. Gibson SLM. 1998. Water Fluoridation - Therapy or Fallacy? Dentistry Issue 24 http://www positive health.com. Retrieved 28-90-2018

8. Hodges PC, Fareed OJ, Ruggy G, Chudnoff JS. 1941. Skeletal sclerosis in chronic sodium fluoride poisoning. JAMA. 117(23):1938. doi:10.1001/jama.1941.02820490012004

9. Kierdorf U, Death C, Hufschmid J, Witzel C, Kierdorf H. 2016. Developmental and Post-Eruptive Defects in Molar Enamel of Free-Ranging Eastern Grey Kangaroos (Macropus giganteus) Exposed to High Environmental Levels of Fluoride. PLoS ONE, 11(2), e0147427. http://doi.org/10.1371/journal.pone.0147427

10. Krook L, Maylin GA. 1979. Industrial Fluoride Pollution: Chronic Fluoride Poisoning in Cornwall Island Cattle. Cornell Vet. Suppl. 8, 69.

11. Li H, Zhang Q, Zhu H. 2012. The size variation and related implications of mandibles in northern China in the past 7000 years. Chinese Science Bulletin Vol.57 No.4: 387-394 doi: 10.1007/s11434-011-4808-1

12. Martinez-Mier EA, Shone DB, Buckley CM, Ando M, Lippert F, Soto-Rojas AE. 2016. Relationship between enamel fluorosis severity and fluoride content. Journal of Dentistry, 46, 42-46. http://doi.org/10.1016/j.jdent.2016.01.007

13. Narayana MV, Chinoy NJ. 1994. Effect of fluoride on rat testicular steroidogenesis. Fluoride 27: 7-12.

14. Proffit WR, Fields HW. 2000. Contemporary orthodontics. 3rd ed. Mosby Inc.

15. Qian C, Li J, Dai GJ. 1989. Effect of high fluoride in drinking water on sexual and physique development of children and adolescent. Chin J Contr Endem Dis. 4:36-37.

16. Robinson C, Connell S, Kirkham J, Brookes SJ, Shore RC, Smith AM. 2004. The effect of fluoride on the developing tooth. Caries Res. 38(3):268-76

17. San-Xiang W, Zheng-Hui W, Xiao-Tian C, Jun L, Zhi-Ping S, Xiang-Dong Z. 2007. Arsenic and Fluoride Exposure in Drinking Water: Children's IQ and Growth in Shanyin County, Shanxi Province. China Environ Health Perspect. 115(4): 643-647

18. Stockton S. 2004. Removing Fluoride From Water - How And Why suzin@healthcarealternatives.net. Retrieved on 30-08-2017

19. Susheela AK, Mondal NK, Gupta R, Ganesh K, Brahmankar S. 2010. Effective interventional approach to control anaemia in pregnant women. Current Science, 98(10):1320-1330.

20. Sutton P. 1996. The Greatest Fraud Fluoridation. ISBN 0949491128. http://www.fluoridation.com/sutton.htm. Retrieved on 22nd May, 2019.

21. Tao S, Zhu Y, Yuan H, Tao S, Cheng Y, Li J, He L. 2018. Efficacy of fluorides and CPP-ACP vs fluorides monotherapy on early caries lesions: A systematic review and meta-analysis. PLoS ONE, 13(4), e0196660. http://doi.org/10.1371/journal.pone.0196660

22. Vinay G, Mangala Gowri SR, Anbalagan J. 2013. Sex determination of human mandible using metrical parameters. Journal of Clinical and Diagnostic Research [serial online]; vol.7; issue $12: 2671-2673$

23. Wang SX, Wang ZH, Cheng XT, Li J, Sang ZP, Zhang XD. 2007. Arsenic and fluoride exposure in drinking water: children's IQ and growth in Shanyin county, Shanxi province, China. Environmental health perspectives, 115(4), 643-647. doi:10.1289/ehp.9270 
Anatomy Journal of Africa. 2020. Vol 9 (1): 1752 - 1761.

24. Waugh DT, Potter W, Limeback H, Godfrey M. 2016. Risk Assessment of Fluoride Intake from Tea in the Republic of Ireland and its Implications for Public Health and Water Fluoridation. International Journal of Environmental Research and Public Health, 13(3), 259. http://doi.org/10.3390/ijerph13030259

25. Xu NY, Huo JX. 2000. Effect of high fluoride on growth of children and adolescent. $J$ Baotou Med Coll. 16:92-95.

26. Yiamouyiannis J. 1990. Water Fluoridation and Tooth Decay: Results from the 1986-1987 National Survey of US School children Fluoride; 23(2):55-67

27. Yiamouyiannis J. 1983. Fluoride the aging factor, Delaware, Ohio: Health Action Press. 22-25: 27: 28-33. 